
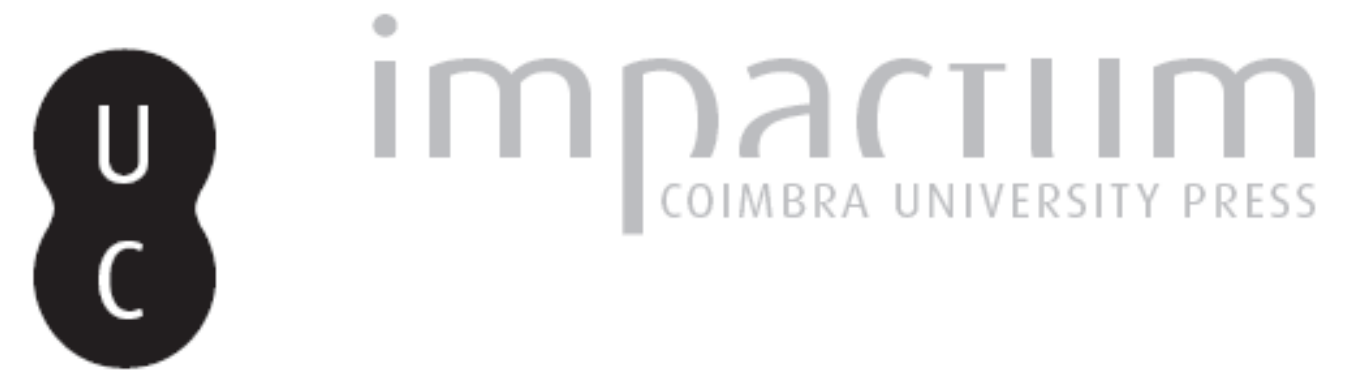

\title{
Rubricas humorísticas das rádios portuguesas como desconstrução da atualidade
}

Autor(es): $\quad$ Pereira, Luís; Ribeiro, Fábio

Publicado por: Imprensa da Universidade de Coimbra

URL persistente:

URI:http://hdl.handle.net/10316.2/38143

DOI:

DOI:http://dx.doi.org/10.14195/2183-5462_27_6

Accessed : $\quad$ 26-Apr-2023 14:53:40

A navegação consulta e descarregamento dos títulos inseridos nas Bibliotecas Digitais UC Digitalis, UC Pombalina e UC Impactum, pressupõem a aceitação plena e sem reservas dos Termos e Condições de Uso destas Bibliotecas Digitais, disponíveis em https://digitalis.uc.pt/pt-pt/termos.

Conforme exposto nos referidos Termos e Condições de Uso, o descarregamento de títulos de acesso restrito requer uma licença válida de autorização devendo o utilizador aceder ao(s) documento(s) a partir de um endereço de IP da instituição detentora da supramencionada licença.

Ao utilizador é apenas permitido o descarregamento para uso pessoal, pelo que o emprego do(s) título(s) descarregado(s) para outro fim, designadamente comercial, carece de autorização do respetivo autor ou editor da obra.

Na medida em que todas as obras da UC Digitalis se encontram protegidas pelo Código do Direito de Autor e Direitos Conexos e demais legislação aplicável, toda a cópia, parcial ou total, deste documento, nos casos em que é legalmente admitida, deverá conter ou fazer-se acompanhar por este aviso. 


\section{Mediag Ornalismo}

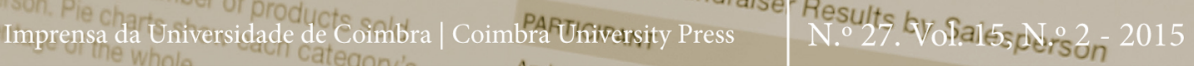

\section{U.m

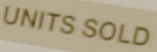 \\ EDUCÂÇÃO PARA OS}

MEDIA NA ERA DIGITAL
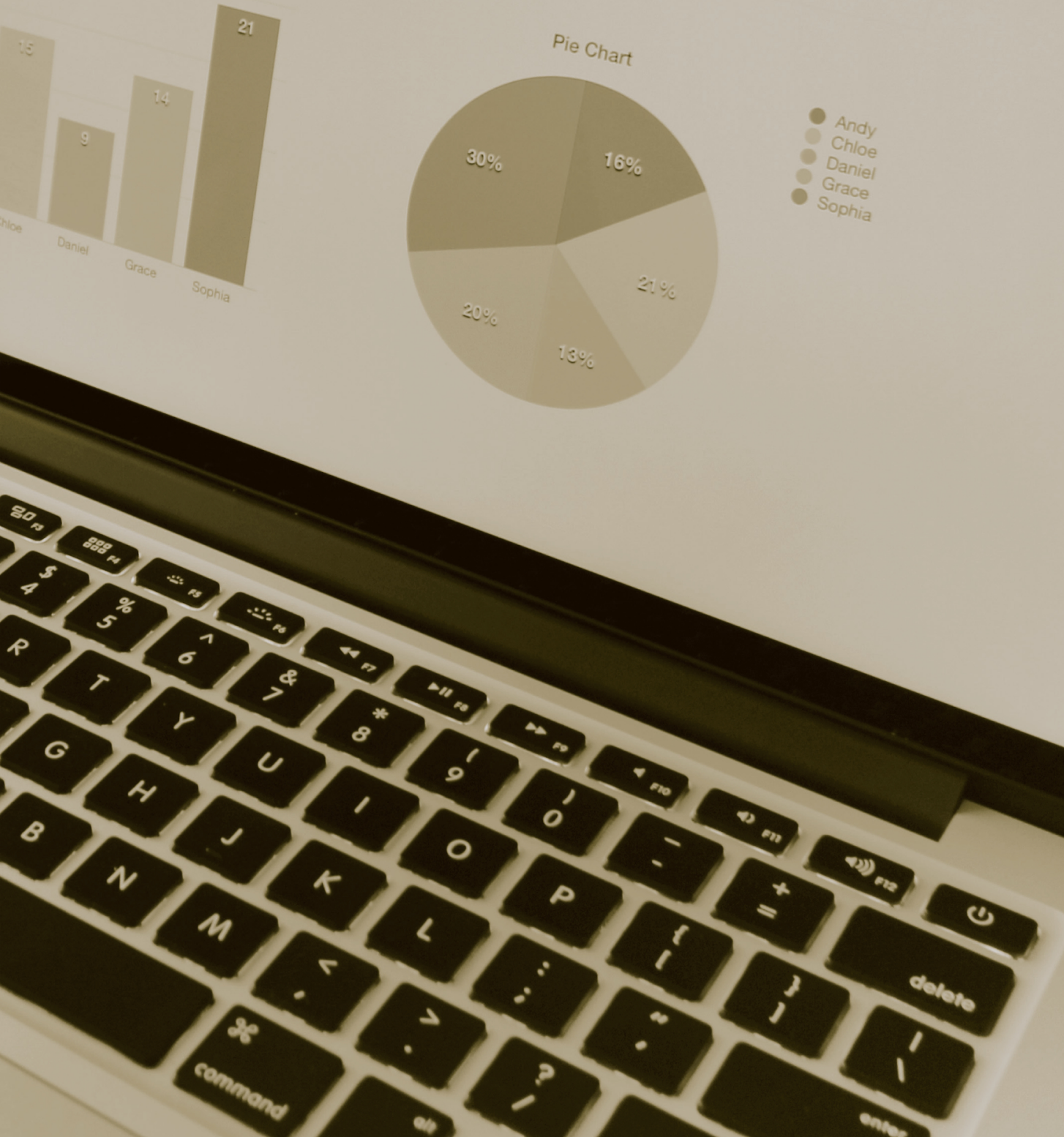


\title{
RUBRICAS HUMORÍSTICAS DAS RÁDIOS PORTUGUESAS COMO DESCONSTRUÇÃO DA ATUALIDADE \\ PARODY IN PORTUGUESE RADIO AS A DECONSTRUCTION OF THE NEWS
}

\author{
LUÍS PEREIRA \\ LUIS.PEREIRA@COVENTRY.AC.UK \\ UNIVERSIDADE DE COVENTRY \\ FÁBIO RIBEIRO \\ FABIOFONSECARIBEIRO@GMAIL.COM \\ UNIVERSIDADE DO MINHO
}

\begin{abstract}
Resumo
A paródia é uma forma de desconstruir a realidade e pode muito bem contribuir para manter as pessoas informadas - sendo esta dimensão informativa uma parte relevante da Educação para os Media. A programação das manhãs da rádio em Portugal apresenta diversos espaços humorísticos. Com esta investigação exploratória pretende-se fazer uma recolha de todos os programas satíricos de curta duração das principais rádios portuguesas para compreender se esses programas têm como tópico a atualidade informativa. Para além da análise de cerca de 50 programas de caráter humorístico, este trabalho inclui ainda dados sobre a percepção de mais de uma centena de ouvintes relativamente à rádio e ao humor. Uma das sugestões dos ouvintes inquiridos é precisamente que os programas satíricos versem mais sobre as temáticas da atualidade política e social.
\end{abstract}

\section{Palavras-chave}

Rádio, humor, educação para os media, atualidade.

\section{Abstract}

Parody is a way to deconstruct reality and may well contribute to keeping people informed, which should be considered a relevant dimension of Media Education. The morning slots in Portuguese radio stations have begun to include satirical programmes. This exploratory research aims to collect all the short duration satirical programmes of the main Portuguese radio broadcasters in order to understand whether these elements satirise ordinary life or political events. In addition to analysing about 50 satirical programmes, this paper also includes the views of around one hundred people on humour and radio. One of the suggestions of listeners is precisely that satirical programs should emphasise topics on political and social parody.

KeYWORDS

Radio, humour, media education, current affairs. 


\title{
RUBRICAS HUMORÍSTICAS DAS RÁDIOS PORTUGUESAS COMO DESCONSTRUÇÃO DA ATUALIDADE
}

\author{
LUÍS PEREIRA \\ LUIS.PEREIRA@COVENTRY.AC.UK \\ UNIVERSIDADE DE COVENTRY \\ FÁBIO RIBEIRO \\ FABIOFONSECARIBEIR0@GMAIL.COM \\ UNIVERSIDADE DO MINHO
}

\section{Introdução}

Nos últimos anos, tem aumentado nos media o espaço e o tempo reservados ao humor. 0 resultado e, ao mesmo tempo, a origem podem ser explicados com fenómenos de popularidade como o do quarteto humorístico 'Gato Fedorento'. Pode-se referir também o 'Contra-Informação' (RTP), o 'Inimigo Público' (suplemento satírico do Público) ou os espaços nas rádios, para além de outros que proliferam na Web. Os humoristas das Produções Fictícias deram para isso um grande contributo, pois o predomínio dos "produtos humorísticos da anedota e do trocadilho no campo do humor em Portugal (...) reservou a estes a exploração de um espaço produtivo herético relativamente à ortodoxia humorística que encontraram quando entraram em campo" (Cantante, 2007, p. 28).

Esta forma de expressão intrínseca ao homem, que lhe permite criticar, zombar, captar a atenção, tem, muitas vezes, uma função de catarse. Segundo Pergher et al. (2005), o humor influencia também o nível de apreensão e memorização da informação, e é para conseguir um nível mais aprofundado de lembrança que a publicidade recorre a esta estratégia. 0 humor acaba ainda por ter a função de informar sobre a atualidade. Seguir estes programas poderá ser uma forma de acompanhar o que se passa no país e no mundo, porque, para que resulte a intenção humorística, é necessário que a audiência conheça minimamente o facto que está a ser glosado, e muitas vezes essa contextualização é feita.

Um dos domínios da Educação para os Media é, segundo o documento Referencial de Educação para os Media, "compreender o mundo atual". Isso passa, entre outros, por "conhecer o que se passa no mundo" (Pereira et al., 2014, p. 15). A ideia subjacente à investigação aqui apresentada procura explorar a hipótese de que conteúdos humorísticos nos media contribuem para que diferentes audiências fiquem a "conhecer os principais assuntos que fazem a atualidade" (ibidem: 18).

Para além da memorização, outro aspecto fundamental no processo humorístico é a criatividade, que se manifesta na

“capacidade projetiva para construir e evocar esquemas e formalizações completas a partir de sinais breves [que] é tal que podemos sobrepor duas projeções cognitivas ao mesmo tempo, fazer sair uma doutra repentinamente ou reformular perspectivas e rapidamente um complexo contexto de situação" (Aladro, 2002, p. 319). 
0 trabalho que aqui se apresenta centra-se na rádio e nos programas humorísticos das manhãs, um período nobre para o meio radiofónico, onde as audiências se concentram em grande número, normalmente entre as sete e as 10 horas. Esta é uma investigação exploratória que se enquadra no projeto de investigação "Estação Net - Moldar a Rádio para o Ambiente Web" (PTDC/CCI-COM/122384/2010). Aqui são apresentados alguns dados de uma recolha e análise de cerca de 50 programas humorísticos de curta duração. São ainda discutidas perspetivas de uma centena de ouvintes sobre a rádio e os programas de humor.

\section{Humor e (Educação para os) Media}

Danna Young, professora de Universidade do Delaware (USA) e autora de diversos textos sobre o humor (2004; 2008), estudou as audiências dos programas de comédia e de sátira política e concluiu que os telespectadores desses programas exibiam um maior nível de familiaridade com as notícias do dia do que as pessoas que não os viam. Consumidores de programas como o 'Inimigo Público' ficam a conhecer 0 que se passa no país e no mundo, porque, para que resulte a intenção humorística, é necessário que estes os conheçam minimamente o facto que está a ser glosado. Meddaugh (2010, p. 377) refere-se a este tipo de notícias como fake news, "um género difícil de definir numa época em que o limiar de informação legítima diminuiu e o esbatimento das fronteiras entre informação e entretenimento - infotainment-é mais evidente".

Outro aspecto fundamental no processo humorístico é a criatividade des-construtiva, que se manifesta na "capacidade projectiva para construir e evocar esquemas e formalizações completas a partir de sinais breves" (Aladro, 2002, p. 319). Em torno deste processo criativo, aparecem questões éticas que o humor deve ter em conta, como destaca o livro editado por Lockyer e Pickering (2005), Beyond a Joke: The limits of humour. Um trabalho da mesma autora, Lockyer (2010: 121), conclui que a comédia televisiva continua a ser um importante espaço onde preocupações, ansiedades e questões sobre identidades e classes sociais são construídas e discutidas. Esse é um dos motivos por que muitas vezes chegam queixas às entidades que têm como missão a regulação dos media (Lunt \& Livingstone, 2012; Sousa \& Silva, 2009).

Internacionalmente, o campo de estudo do humor e dos media tem vindo a ser desenvolvido, como se pode ver, por exemplo, no Reino Unido, com a criação, em 2013, do Centre for Comedy Studies Research, que tem dinamizado seminários e publicações relacionadas com o humor e os media; e com investigações como 0 projeto "Make Me Laugh", da Universidade inglesa de East Anglia, que explorou a criatividade da indústria televisiva relacionada com a comédia. Em Portugal, é relevante 0 trabalho de Dias da Silva e Garcia (2012), onde se discute o papel do humor na política, bem como a sátira na era digital e o relevo que assume o vídeo no Youtube, por exemplo.

Gray (2005) nota, por outro lado, que a paródia televisiva potencia a educação para os media, pois o poder da comédia e do entretenimento permitem elucidar sobre técnicas e sobre a retórica dos textos e géneros televisivos. Outros autores sugerem nesta mesma linha o humor e a paródia como bons recursos para o desen- 
volvimento de competências de literacia mediática (Stark, 2003; Meddaugh, 2010; Pereira et al., 2009; 2011).

A isto, deve acrescentar-se que o humor é um dos tópicos mais apreciados pelos jovens, como o comprovam os estudos sobre televisão realizados por Pinto (2000) e Pereira, Pinto e Pereira (2009). Outros trabalhos debruçam-se sobre a preferência das audiências, como Lockyer (2011), especificamente sobre stand-up comedy, ou Meddaugh (2010), que sublinha que os jovens, em particular, procuram cada vez mais fontes alternativas de informação com programas como 'Daily Show' ou 'Tonight Show'. Por outro lado, têm sido também exploradas as vantagens do humor na implementação da educação para os media. É o caso de Armstrong (2005), Garcia et al. (2013, p. 115) e Shelton (2014), autores que dão conta dos resultados positivos da exploração do registo humorístico para desenvolver competências de educação para os media. Stark (2003, p. 305) descreve a sátira como uma ferramenta muito eficaz para o ensino de educação para os media. Num outro trabalho realizado por um autor deste texto (Pereira, no prelo) descreve-se um processo de formação, sob a forma de workshop, de professores, bibliotecários ou investigadores que pretendia encorajar estes educadores a tirar partido do humor para fomentar a literacia digital.

Ao tentar perceber em que medida a dimensão da atualidade se insere nos programas de humor, este estudo está em linha com várias sugestões referidas no já mencionado Referencial de Educação para os Media. Com efeito, este documento deixa orientações a professores, educadores, investigadores e público em geral para desenvolverem esforços consistentes para uma melhor compreensão do mundo atual. No ponto dedicado a este assunto, o Referencial sugere a promoção da "curiosidade e interesse pelos acontecimentos da atualidade" (Pereira et al., 2014, p. 17), para que os cidadãos possam aprender a expressar e a debater as suas opiniões em relação às notícias que marcam a agenda mediática atual. Neste sentido, os programas de humor, recorrendo a possíveis registos satíricos ou irónicos no discurso, podem conduzir os ouvintes a uma melhor compreensão do mundo, desconstruindo personagens, contextos e notícias que fazem parte do palco mediático por onde o quotidiano se constrói.

\section{Estudo exploratório sobre programas humorísticos na rádio portuguesa}

Este trabalho pretende identificar, recolher e analisar programas/rubricas de humor das principais emissoras de rádio em Portugal, em torno das seguintes questões: de que forma os programas de humor na rádio utilizam a atualidade como eixo prioritário do discurso? Que estratégias utilizam para a desconstrução do mundo e da atualidade noticiosa (um dos objetivos a que educação para os media tenta responder)?

A partir da explanação teórica descrita anteriormente, onde foram identificados aspetos importantes relativos ao contributo dos formatos humorísticos nos media para a leitura crítica e atualizada do mundo, é apresentada nesta fase uma reflexão de âmbito metodológico que visa cruzar diferentes técnicas de observação implementadas justamente para analisar programas e rubricas de humor na rádio em Portugal. Deste modo, entendemos o humor radiofónico num sentido clássico, ou 
seja, um formato autónomo, inserido na grelha de programação, protagonizado por um ou mais intervenientes e que utiliza fundamentalmente um discurso humorístico. Neste sentido, utilizámos duas técnicas de recolha de dados:

1. identificação de programas/rubricas de humor e análise formal e substantiva das dinâmicas narrativas que se podem encontram nesses espaços;

2. análise de dados provenientes de um inquérito por questionário a ouvintes de rádio e dos programas humorísticos.

\subsection{IDENTIFICAÇÃO E ANÁLISE FORMAL DE PROGRAMAS DE HUMOR NA RÁDIO}

Neste primeiro momento metodológico, importa compreender de que forma as principais rádios portuguesas se organizam para construir uma grelha de programação que contemple programas/rubricas de humor. Deste modo, seguimos a mais recente base de dados disponível para a consulta de audiências, a vaga de setembro de 2014 do Bareme Rádio1. Conforme explica a Tabela 1, estas são as dez rádios mais ouvidas:

\begin{tabular}{|c|c|c|}
\hline Posição & Emissoras de rádio & Share de Audiência (\%) \\
\hline $\mathbf{1 .}^{\mathbf{0}}$ & Rádio Comercial & 24,1 \\
\hline $\mathbf{2 .}^{\mathbf{0}}$ & RFM & 21,6 \\
\hline $\mathbf{3 .}^{\mathbf{0}}$ & Renascença & 7,7 \\
\hline $\mathbf{4 .}^{\mathbf{0}}$ & Antena 1 & 6,4 \\
\hline $\mathbf{5 .}^{\mathbf{0}}$ & M80 & 5,5 \\
\hline $\mathbf{6 .}^{\mathbf{0}}$ & Cidade & 4,6 \\
\hline $\mathbf{7 .}^{\mathbf{0}}$ & TSF & 3,5 \\
\hline $\mathbf{8 .}^{\mathbf{0}}$ & MegaHits & 2,9 \\
\hline $\mathbf{9 .}^{\mathbf{0}}$ & Antena 3 & 2,8 \\
\hline $\mathbf{1 0}{ }^{\circ}$ & Rádio SIM & 2,7 \\
\hline
\end{tabular}

Tabela 1 - As dez emissoras de rádio com maior percentagem de share de audiências. Fonte: Bareme Rádio, Vaga setembro 2014.

1 Acedido através de [http://www.marktest.com/wap/a/n/id 1de8.aspx], publicado a 14 de outubro de 2014 e consultado em 20 de outubro de 2015. 
Do ponto de vista da esquematização temática das rádios apresentadas, poderíamos distinguir, embora superficialmente, dois grupos de emissoras: as rádios temáticas que apresentam "conteúdos muito uniformes, mas com recurso a alguma diversidade de programas ou rubricas (...) funcionam como um contínuo, sendo 0 melhor exemplo as rádios musicais de play list" (Garcia \& Bailén cit. por Ribeiro: 2008, p. 14); e as rádios informativas que "dedicam uma atenção muito particular à atividade jornalística, como o relato de notícias, reportagens e os outros géneros de jornalismo, a entrevista ou a crónica" (Ribeiro, 2008, p. 19). Ainda que esta classificação possa incluir outras considerações teóricas mais afinadas, poderíamos ainda assim concluir que apenas duas em dez rádios desempenham, prioritariamente, a função de emissoras informativas (Antena 1 e TSF). Sete habitam no terreno da tematização radiofónica musical (Rádio Comercial, RFM, M80, Cidade, MegaHits, Antena 3e Rádio SIM) e a Renascença, pela sua importante vertente informativa com a produção de variados conteúdos para diversos géneros jornalísticos, como a entrevista, reportagem, noticiário, crónica, etc. -, inserida numa inclinação também musical, poderia ser descrita como uma rádio de estilo híbrido.

Depois de uma observação mais genérica, importa porventura considerar de que forma os programas/rubricas de humor concorrem para a compreensão crítica do mundo que, no fundo, resume a principal questão de investigação aqui lançada. Assim, recorrendo a uma amostra temporal de observação de emissões de uma semana, isto é, entre 1 e 7 de fevereiro de 2015, construímos a Tabela 2, que introduz os critérios pelos quais a análise detalhada subjacente a cada programa.

\begin{tabular}{|l|l|}
\hline $\mathbf{N}^{\mathbf{0}}$ & \multicolumn{1}{c|}{ Critérios para a análise dos programas de humor } \\
\hline $\mathbf{1}$ & Horário \\
\hline $\mathbf{2}$ & Apresentação \\
\hline $\mathbf{3}$ & Duração (aproximadamente, em minutos) \\
\hline $\mathbf{4}$ & Convidados \\
\hline $\mathbf{5}$ & Interação com ouvintes \\
\hline $\mathbf{6}$ & Informação autónoma (site, redes sociais, etc.) \\
\hline $\mathbf{7}$ & Adequação dos temas à atualidade mediática \\
\hline $\mathbf{8}$ & Formatos mediáticos glosados \\
\hline $\mathbf{9}$ & Presença do humor no texto \\
\hline $\mathbf{1 0}$ & Construção da narrativa humorística \\
\hline
\end{tabular}

Tabela 2 - Critérios de análise dos programas de humor na rádio.

Os critérios apresentados procuram conferir alguma organização à observação que se seguiu. Assim, registámos informações relativas ao horário habitual da emissão do programa, apresentação, duração em média da rubrica, presença de convidados ou se são promovidas algumas políticas de interação com os ouvintes. No entanto, como aspeto mais importante, analisámos se os temas apresentados estão em sintonia com a atualidade mediática e jornalística e quais os formatos que tentam recriar/imitar no discurso (entrevista, crónica, reportagem, noticiário, etc.). 
A Tabela 3 procede a esse primeiro passo de observar o número de formatos humorísticos existentes na rádio em Portugal:

\begin{tabular}{|c|c|c|}
\hline Emissoras de rádio & $\begin{array}{l}\text { Número de formatos } \\
\text { humorísticos }\end{array}$ & Descrição \\
\hline \multirow{3}{*}{ Rádio Comercial } & \multirow{3}{*}{3} & 'Mixórdia de Temáticas' \\
\hline & & 'O Homem que Mordeu o Cão' \\
\hline & & 'Moços de Recados' \\
\hline \multirow{3}{*}{ RFM } & \multirow{3}{*}{3} & 'A Vida de Unas' \\
\hline & & 'Pensa Rápido' \\
\hline & & 'NILTON' \\
\hline Renascença & 0 & - \\
\hline Antena 1 & 1 & 'Portugalex' \\
\hline M80 & 1 & 'Cromos M80' \\
\hline Cidade & 0 & - \\
\hline TSF & 1 & 'Tubo de Ensaio' \\
\hline MegaHits & 0 & - \\
\hline \multirow{3}{*}{ Antena 3} & \multirow{3}{*}{3} & 'Outra Coisa' \\
\hline & & 'Não Digo Nomes' \\
\hline & & 'Portugalex' \\
\hline Rádio SIM & 0 & - \\
\hline
\end{tabular}

Tabela 3 - Tabela de programas/rubricas de humor na rádio em Portugal, nas dez emissoras mais ouvidas.

As dez rádios mais ouvidas em Portugal propõem um total de 12 programas humorísticos, sendo que quatro dessas emissoras (quase metade do total) não têm qualquer formato deste género. A concentração reside, pois, na Rádio Comercial, RFM e Antena 3, todas com três formatos cada. M80, TSFe Antena 1 têm uma rubrica de humor cada. Tendo em conta esta observação, analisemos em detalhe os formatos humorísticos considerados, a partir de critérios definidos na Tabela 2.

\subsubsection{Rádio Comercial: 'Mixórdia de Temáticas', 'O Homem que Mordeu o Cão' E 'Moço de Recados'}

Provavelmente um dos formatos mais conhecidos da estação, aproveitando também o crescente mediatismo do autor deste espaço - Ricardo Araújo Pereira -, a 'Mixórdia de Temáticas' ia para 0 ar de segunda a sexta-feira sensivelmente às $8 \mathrm{~h} 15$, repetindo às $9 \mathrm{~h} 15$ e 19h15, inserido nas 'Manhãs da Comercial', entre as 7 e as 10h, dos dias úteis, desde 2012. É um formato radiofónico de crónica de autor sobre assuntos tendencialmente atuais, mas que versam igualmente questões do quotidiano, da economia familiar, das relações sociais, etc. Em termos médios, tem uma duração de cinco minutos e dispõe de um site, onde é possível aceder ao podcast e arquivo de programas².

2 Site em: www.radiocomercial.iol.pt/player/mixordia_de_tematicas.aspx, consultado em 01-02-2015. Página do Facebook em: www.facebook.com/RadioComercial.Mixordiadetematicas, consultado em 01-02-2015. 
Ao longo das cinco emissões analisadas, tentámos identificar se algum dos temas levados à antena constituíam parte da agenda noticiosa do dia, ou até dos anteriores ${ }^{3}$. Concluímos que em todas as emissões são reportadas narrativas para preencher um universo cómico irrealista, embora pontualmente 0 autor recupere aspetos quotidianos realistas (Emissões 3 e 4). 0 formato mediático mais glosado nesta crónica foi o da entrevista, em que a personagem ou o apresentador interage através de questões colocadas pelos locutores.

Se o formato anterior faz parte de uma nova aposta da Rádio Comercial no humor, 'O Homem que Mordeu o Cão', da autoria de Nuno Markl, começou a ser emitido em 1997. Vai para 0 ar de segunda a sexta-feira, em duas edições às 8h50 e 9h50. 0 programa recupera frequentemente as contribuições de ouvintes (potenciadas através da página do Facebook do programa ${ }^{4}$ que procuram facultar ao apresentador estas informações. Não dispõe de convidados e tem uma duração média aproximada de sete a oito minutos, ocupando habitualmente os últimos minutos da emissão até aos noticiários das 9h e 10h. A produção disponibiliza um site, podcaste uma página do Facebook, o que aparentemente configura uma estratégia com bastante agilidade para promover a escuta dos episódios depois da emissão em direto ${ }^{5}$.

Do ponto da vista da adequação do formato à temática da atualidade, podemos considerar que 'O Homem que Mordeu o Cão' respira precisamente a partir de assuntos que estão inseridos na atualidade mediática; no entanto, a utilização da atualidade não pretende desconstruir o discurso jornalístico. A tónica humorística está permanentemente presente ao longo de toda a rubrica, entrecortada com o registo real das estórias contadas ${ }^{6}$. Naturalmente que 0 caráter inesperado das situações contadas pelo apresentador acrescentam uma grande dose de comicidade ao formato, tal como se pode depreender dos títulos das emissões reportadas. Aliás, a forma como o humorista apresenta cada episódio, referindo o título enquanto decorre o genérico - que apela ao contexto sonoro de cães a ladrar - relembra claramente o discurso típico do jornalismo televisivo ou radiofónico de elaboração de teasers, de chamadas apelativas para captar a atenção do espectador ou ouvinte. Como foi observado nas Emissões 1 e 3, as notícias são retiradas de fontes de jornais americanos ou britânicos, mas nem sempre há informação detalhada a este respeito, embora também seja provável encontrar referências a documentação encontrada em sites ou blogues de grupos de interesses. A leitura do texto, feita pelo apresentador e que decorre também da interpelação direta dos restantes apresentadores

30 formato contou com os seguintes assuntos: Borrasca festiva indivíduo (Emissão 1); Portugal calça indivíduo (Emissão 2); Conversa com vegetação, mano (Emissão 3); Polémica na ingestão de fruta (Emissão 4); Cinema do bom (Emissão 5).

4 Disponível em: www.facebook.com/homemcao

5 Disponível em: http://radiocomercial.iol.pt/player/homem_que_mordeu_0_cao.aspx

6 Os títulos das emissões observadas são: Emissão 1: "Quero dormir de botas calçadas"; Emissão 2: "Queres dar à luz em Marte? Sim? Não?"; Emissão 3: "Tantantarantan Jesus"; Emissão 4: Quero voltar à escola num Lamborghini"; Emissão 5: "Onde estão as rapidinhas de escritório de antanho?"; Emissão 6: "Vamos a ver se isto agora corre em condições"; Emissão 7: "A vingança serve-se amarela"; Emissão 8: "Justin Bieber num foguetão". De referir que no dia 4 de fevereiro de 2015, o programa não foi emitido. 
das 'Manhãs da Comercial', é realizada recorrendo ao ênfase de certas expressões, tal e qual como no relato típico de um noticiário. As gargalhadas do elenco, outro elemento que se presta à atmosfera cómica, é parte indissociável do discurso.

Quanto à rubrica 'Moços de Recados', a mais recente de todas nas 'Manhãs da Comercial', foi emitida de segunda a sexta-feira poucos minutos antes das 9h30, habitualmente, desde novembro de 2014. De acordo com o site', 'Moços de Recados' "é o mural de mensagens" dos ouvintes. Como se depreende, esta rubrica existe fundamentalmente a partir da interação com os ouvintes e insere-se numa lógica distinta dos dois formatos anteriores considerados. Não utilizava qualquer ligação à atualidade mediática. A apresentação estava a cargo de um dos membros da equipa das 'Manhãs'. Este acaba por ser um dos formatos mais curiosos por transmitir a sensação de uma rádio ainda mais próxima dos ouvintes, com informações sobre impossibilidade de chegar a tempo a uma reunião, ou avisos a vizinhos sobre como estacionar no parque (Emissão 3).

\subsubsection{RFM: 'A Vida de Unas', 'Pensa Rápido' e 'NiLTon'}

Recentemente integrada no 'Café da Manhã' da RFM, a rubrica 'A Vida de Unas', do humorista e ator Rui Unas, é uma crónica humorística que propõe um tema de conversa com os locutores habituais deste espaço matinal. Nas emissões observadas - quatro -, não foi possível identificar qualquer tema pertencente ao discurso mediático da atualidade ${ }^{8}$. Na Emissão 3 houve uma referência a uma notícia publicada pelo jornal francês Le Monde; no entanto, não foram abordados quaisquer aspetos relativos à forma como o jornalismo analisou a questão, apenas de contextualização.

0 programa tem uma duração média de 5 a 7 minutos e está sempre disponível para consulta no site da RFM em podcast ${ }^{\dagger}$. Não promove a interação com ouvintes, nem apresenta convidados. Em termos da presença do humor ao longo do texto do programa, percebe-se que existe um substrato da realidade que serve de contexto ao tema apresentado, para posteriormente 0 apresentador introduzir apontamentos de natureza humorística, recorrendo ao diálogo com os locutores, comentários politicamente incorretos (Emissão 1) ou a críticas estereotipadas a mulheres (Emissão 2).

A rubrica 'Pensa Rápido' vai para o ar desde junho de 2014 na RFM, de segunda a sexta-feira, ao fim da tarde, pelas 17h35. Salvador Martinha, 0 apresentador, partilha pensamentos, ideias, considerações avulsas sobre o quotidiano em jeito de crónica de autor. Através das cinco emissões analisadas, não identificámos qualquer tema pertencente à atualidade mediática ${ }^{10}$. 0 formato não se presta à interação com ouvintes nem à inscrição de convidados e tem uma duração de aproxima-

7 Disponível em: http://radiocomercial.iol.pt/player/recados.aspx

8 Temas dos formatos observados: Emissão 1: Truques para viver mais tempo; Emissão 2: as muIheres andam nervosas desde a interrupção de 'Anatomia de Grey'; Emissão 3: aumento dos mamilos; Emissão 4: namorado perfeito.

9 Disponível em: http://rfm.sapo.pt/podcast/37499/

10 Temas observados: Emissão 1: "Vida em Marte"; Emissão 2: "Perder Coisas"; Emissão 3: "Racionamento de água"; Emissão 4: "Motas na faixa do bus"; Emissão 5: "Arrastar cadeiras". 
damente cinco minutos; disponibiliza os conteúdos em podcast através do site ${ }^{11}$. 0 formato apresenta um estilo relativamente conhecido, glosando o formato de notícia para consequente explanação humorística. Do ponto de vista sonoro, apresenta recursos muito variados e que contextualizam praticamente todo o discurso do apresentador: a porta que bate, 0 arrastar de cadeiras (Emissão 5), a perseguição pela polícia (Emissão 4), as chaves ou a campainha (Emissão 2). Nesta edição, percebemos ainda a presença de um ambiente cinematográfico que envolve novamente a narrativa, com sons de suspense que contextualizam uma questão que 0 apresentador coloca.

A rubrica homónima do apresentador que a dirige - 'Nilton' - representa o formato mais antigo dos considerados até ao momento na RFM (desde 2012). Embora sem horário fixo, a presença de Nilton no 'Café da Manhã' decorre sempre no espaço matinal e assume várias sub-rubricas: '0 teu pai tem bigode', crónicas de autor sobre assuntos do quotidiano; 'Telefonema do Nilton', com excertos de inesperadas chamadas telefónicas em que 0 apresentador entra em contacto com um determinado indivíduo para Ihe propor questões surreais; e o 'Livro de Reclamações', em que a personagem interpretada por Nilton fala sobre aspetos diários que 0 incomodam. De um modo genérico, esta rubrica tem uma duração média de 5 minutos.

Encontrámos na sub-rubrica '0 teu pai tem bigode'12 exemplos que representam o princípio de desconstrução humorística da realidade, tendo os media como pano de fundo. Assim, na Emissão 2, a ascensão do partido grego Syriza ao poder foi 0 tema central da narrativa e, na Emissão 3, explica a prisão do ex-primeiro-ministro José Sócrates. Em resumo, das cinco observações, duas desmontam o universo da atualidade mediática, recorrendo ao humorismo. Quanto aos formatos mediáticos glosados pela rubrica de humor, registámos a entrevista (Emissão 1, 2 e 5) e a crónica (Emissão 3).

\subsubsection{Antena 1: 'Portugalex'}

Apresentado pelos atores António Machado e Manuel Marques, 'Portugalex' tem emissão marcada para as $7 \mathrm{~h} 55$ e repetição às $12 \mathrm{~h} 25$, de segunda a sexta-feira, desde 2011. Ao longo de aproximadamente cinco minutos, os dois apresentadores lançam notícias da atualidade, ao estilo de um noticiário radiofónico, para completarem o restante enquadramento com uma narrativa humorística ficcionada. Através de um site, onde é possível consultar os últimos programas em arquivo, e de uma página no Facebook, a produção disponibiliza os conteúdos do programa ${ }^{13}$.

A análise das cinco emissões revela que todos os temas que serviram de base ao discurso humorístico constituem parte do que temos vindo a definir como atu-

11 Disponível em: http://rfm.sapo.pt/podcast/37334/

12 Os temas das emissões foram: Emissão 1: "Ligue 760 qualquer coisa"; Emissão 2: "0 Partidos dos Tios Radicais"; Emissão 3: "Entrevista a Sócrates"; Emissão 4: "Luso Com Gás? Não é perigoso?"; Emissão 5: "Dou conta de tudo".

13 Disponível em: https://www.facebook.com/Portugalexrtp; http://www.rtp.pt/play/p293/ e182557/portugalex 
alidade noticiosa mediática, o que configura, neste estudo, um caso único ${ }^{14}$. Em termos de formatos mediáticos glosados, o noticiário é aquele que mais se destaca em todas as emissões, embora também foi possível registar a reportagem (Emissão 1) e o fórum de opinião pública (Emissão 1 e 4). Na Emissão 1, fala-se sobre a polémica da nomeação de um novo padre em Vila Nova de Gaia, que gerou a insatisfação da população local, com uma suposta reportagem no local onde vários populares se insurgem. Depois, uma notícia sobre a produção de água potável a partir de fezes humanas, mediatizada pela utilização por parte do patrão da Microsoft, Bill Gates. Esta notícia foi o mote para a dinamização de um fórum radiofónico, que recebeu as contribuições da responsável pelo Banco Alimentar e de um reformado de Rio Tinto, uma voz que representa um grupo tradicionalmente associado ao auditório típico destes programas. Na Emissão 4, os locutores perguntam se a ascensão do partido grego Syriza já mudou a vida dos ouvintes. Na última edição analisada, houve espaço para a notícia que dava conta de dez jihadistas britânicos que moraram em Sintra antes de integrarem as fileiras do Estado Islâmico na Síria.

Do ponto de vista da construção da narrativa humorística, já demos aqui algumas informações importantes, como a forma de leitura do noticiário, o genérico ou a imitação de vozes, que fazem parte do guião em todas as emissões. A convivência entre a realidade e a ficção nota-se frequentemente ao longo de todo o texto. Do ponto de vista sonoro, existem efeitos que pretendem atribuir mais credibilidade ao formato. 0 barulho de uma multidão que se amontoa para dar uma opinião numa manifestação (Emissão 1), o efeito do som do telefone antes do iniciar do fórum ou o som do bar onde o ouvinte dá a sua opinião (ambos na Emissão 4) constituem recursos positivos para a construção do imaginário sonoro da rubrica. Sublinhamos ainda a repetição da expressão "rigoroso exclusivo do 'Portugalex'", um velho chavão do jornalismo, para certificar a aproximaç̧ão do discurso humorístico ao do noticiário.

\subsubsection{TSF: 'Tubo de Ensaio'}

Este programa recupera algumas das questões assinaladas no programa 'Portugalex', observado anteriormente, mas importa esclarecer algumas diferenças relevantes. De acordo com informação no site da TSF ${ }^{5}$, o 'Tubo de Ensaio' representa um formato de "noticiários em jeito de stand-up, entrevistas ficcionadas, temas 'quentes', coisa que irritam, projetos para o futuro". Com a colaboração de textos de João Quadros, Bruno Nogueira apresenta esta rubrica ao longo de, aproximadamente, três a quatro minutos, de segunda a sexta-feira às $8 \mathrm{~h} 40$, com repetição às $18 \mathrm{~h} 25$ e $20 \mathrm{~h} 15$ e compacto semanal aos domingos, às $16 \mathrm{~h} 35$.

14 De acordo com a informação do site, os temas foram: Emissão 1: “Fórum: Era capaz de beber água de cocó?"; Emissão 2: "Cavaco Silva revela conversas com Ricardo Salgado"; Emissão 3: " Sócrates luta por saco de água quente "; Emissão 4: "Fórum - A vitória do Syriza já está a mudar a sua vida?"; Emissão 5: "Agente imobiliária de jihadistas em Portugal".

15 Disponível em: http://www.tsf.pt/Programas/programa.aspx?content_id=904110\&audio_ id $=4393809$ 
Em termos da adequação deste programa à realidade e atualidade mediática, verificámos que quatro das cinco emissões observadas utilizaram justamente este propósito de dinamização da rubrica humorística ${ }^{16}$. Na Emissão 1, Bruno Nogueira explora a notícia sobre a alegada conversa entre o Presidente da República e o ex-presidente do Banco Espírito Santo, Ricardo Salgado, bem como a vitória do Syriza. Na Emissão 2, o humorista reflete sobre a carta enviada por um deputado do PSD a Alexis Tsipras. Na terceira edição, a crónica debate a nova lei promulgada pela Câmara Municipal de Lisboa, que proíbe a circulação de automóveis com matrícula entre 1996 e 2000, entre as 7 e as 21 horas dos dias úteis no centro da cidade. Na quinta, Nogueira aborda a polémica instalada com a negociação do governo sobre 0 tratamento da hepatite $\mathrm{C}$ e as declarações do Primeiro-Ministro Pedro Passos Coelho, que referia que o Ministério de Saúde deveria encontrar a solução mais ajustada, mas "não a todo o custo". De referir que a Emissão 4 recorreu a um tema que não é inscrito na atualidade, sobre as dificuldades de colocação do baton pelas mulheres.

\subsubsection{Antena 3: 'Outra Coisa' e 'Não Digo Nomes'}

Os recursos vocais de Luís Franco-Bastos, nomeadamente de imitação exímia de vozes de personalidades da vida pública portuguesa e internacional, eram 0 principal eixo de toda a dinâmica narrativa do humor em 'Outra Coisa', no ar de segunda a sexta-feira, às $8 \mathrm{~h} 25$ e com repetições às $18 \mathrm{~h} 20$ e às $7 \mathrm{~h} 20$ do dia seguinte, desde setembro de 2012. 0 programa, com textos de Filipe Homem Fonseca, está disponível no site, em podcast ${ }^{17}$, em programas de curta duração, habitualmente de cinco minutos.

Durante as cinco emissões analisadas, o programa recuperou sempre aspetos da atualidade e tentou, justamente, desmontá-los recorrendo sobretudo à imitação de vozes e aos diálogos fictícios ${ }^{18}$. 0 formato mediático preferencial foi 0 da entrevista, através da apresentação do tema pelos locutores e da entrada das personagens. Assim, na Emissão 1, Cavaco Silva, utilizando um discurso confuso, refere que nunca falou com Ricardo Salgado, do BES, argumentando que esse banco está "sólido", aludindo às declarações do Presidente em 2014 na Coreia do Sul e que foram recentemente recuperadas pelos media. Na segunda, Marcelo Rebelo de Sousa comenta a atualidade da Grécia e, na terceira, Pedro Passos Coelho fala também sobre a Grécia. Na quarta edição, destaca-se a notícia do tribunal francês que proibiu que dois franceses chamassem à sua filha Nutella, por conotações comerciais impedidas por lei. Na última observação, houve espaço para a antevisão do jogo Sporting/Benfica.

16 De acordo com informações disponibilizadas no site, os temas das emissões foram: Emissão 1: "Resumo da 1"a semana dos malucos gregos"; Emissão 2: "A carta de Duarte"; Emissão 3: "Xenofobia de matrícula"; Emissão 4: "Saber aplicar baton"; Emissão 5:" Os hepáticos que paguem a crise".

17 Disponível em: http://www.rtp.pt/programa/radio/p5307

18 De acordo com informações disponibilizadas no site, os temas das emissões foram: Emissão

1: " Cavaco enfrenta o vagalómetro!"; Emissão 2: "0 Prof. Marcelo comenta Grécia, educação e BES"; Emissão 3: " Passos Coelho fala sobre a Grécia... mais ou menos. "; Emissão 4: " 0 protesto do Sr. Sem Glúten"; Emissão 5:" A antevisão do dérbi". 
A rubrica 'Não Digo Nomes' integrava, como a anterior, a programação das 'Manhãs da 3', e é apresentada por Serginho, de segunda a sexta-feira às 9h15, com repetição às 7 h45 do dia seguinte. Assumindo a forma de uma crónica de autor, versa questões do quotidiano, ao estilo de pensamentos soltos sobre determinados assuntos, ao longo de, em média, dois minutos. A disponibilização de conteúdos surge apenas na página oficial do programa ${ }^{19}$.

A adequação à atualidade mediática é total, na medida em que todas as cinco edições observadas recuperam aspetos noticiosos que tiveram lugar nos media ${ }^{20}$. Assim, na primeira, os anúncios publicitários sobre o Dia dos Namorados assinalam 014 de fevereiro: na Emissão 2, há uma referência à candidatura de Luís Figo à FIFA; na terceira observação, o humorista destacou o frio que se sentia em Portugal; na quarta, o humorista recupera a informação sobre a localização do avião que se despenhou, em 1961, nos Andes chilenos, com uma equipa de futebol. A derradeira emissão dava conta do esquema montado por quatro reformados que assaltaram residências em várias zonas do país, fazendo referência implícita a acontecimentos reais.

\subsection{Súmula dOS DADOS E PERSPETIVA DOS OUVINTES}

0 Quadro 1 destaca, dentre os programas analisados, aqueles que, de forma central (sublinhados a cor escura) ou meramente en passant(sublinhados a cor mais clara), tocam assuntos da atualidade. Quanto aos restantes, sem qualquer sublinhado, significa que não foram vislumbradas quaisquer referências a eventos políticos, culturais ou sociais que marcavam a realidade informativa do momento. Apesar de a amostra ser muito pequena, tratando-se de uma semana apenas, verifica-se que 24 programas entram na primeira lista, aqueles com algum tipo de ligação à realidade, ao passo que os restantes 23 não o fazem. Ou seja, a divisão é quase equitativa. Por outro lado, verifica-se a repetição de assuntos que claramente marcavam a atualidade, como foi 0 caso das eleições na Grécia.

19 Disponível em: http://www.rtp.pt/programa/radio/p5396

20 De acordo com informações disponibilizadas no site, os temas das emissões foram: Emissão 1: "Na app"; Emissão 2: "FIFA"; Emissão 3: "Polar"; Emissão 4: "Humor negro"; Emissão 5:"Terceira idade". 


\begin{tabular}{|c|c|c|c|c|c|c|c|c|c|}
\hline & \multicolumn{2}{|c|}{ 02Fev'15 } & \multicolumn{2}{|c|}{ 03Fev'15 } & 04Fev'15 & \multicolumn{2}{|c|}{ 05Fev'15 } & \multicolumn{2}{|c|}{ 06Fev'15 } \\
\hline $\begin{array}{l}\text { 'A Vida de } \\
\text { Unas' }\end{array}$ & \multicolumn{2}{|c|}{$\begin{array}{l}\text { Truques para viver } \\
\text { mais tempo }\end{array}$} & \multicolumn{2}{|c|}{$\begin{array}{l}\text { As mulheres andam } \\
\text { nervosas desde a } \\
\text { interrupção de } \\
\text { 'Anatomia de Grey' }\end{array}$} & $\begin{array}{l}\text { Aumento } \\
\text { dos } \\
\text { mamilos }\end{array}$ & \multicolumn{2}{|c|}{ Namorado perfeito } & \multicolumn{2}{|c|}{-} \\
\hline $\begin{array}{l}\text { 'Mixórdia de } \\
\text { Temáticas' }\end{array}$ & \multicolumn{2}{|c|}{$\begin{array}{l}\text { Borrasca festiva } \\
\text { individuo }\end{array}$} & \multicolumn{2}{|c|}{ Portugal calça indivíduo } & $\begin{array}{l}\text { Conversa } \\
\text { com } \\
\text { vegetação, } \\
\text { mano }\end{array}$ & \multicolumn{2}{|c|}{$\begin{array}{c}\text { Polémica na ingestão } \\
\text { de fruta }\end{array}$} & \multicolumn{2}{|c|}{ Cinema do bom } \\
\hline $\begin{array}{l}\text { 'Não Digo } \\
\text { Nomes' }\end{array}$ & \multicolumn{2}{|c|}{ Na app } & \multicolumn{2}{|c|}{ FIFA } & Polar & \multicolumn{2}{|c|}{ Humor negro } & \multicolumn{2}{|c|}{ Terceira Idade } \\
\hline 'Nilton' & \multicolumn{2}{|c|}{$\begin{array}{c}\text { Ligue } 760 \text { qualquer } \\
\text { coisa }\end{array}$} & \multicolumn{2}{|c|}{$\begin{array}{l}0 \text { Partido dos Tios } \\
\text { Radicais }\end{array}$} & $\begin{array}{c}\text { Entrevista a } \\
\text { Sócrates }\end{array}$ & \multicolumn{2}{|c|}{$\begin{array}{l}\text { Luso Com Gás? } \\
\text { Não é perigoso? }\end{array}$} & \multicolumn{2}{|c|}{ Dou conta de tudo } \\
\hline $\begin{array}{l}\text { '0 Homem } \\
\text { que Mordeu } \\
\text { o Cão' }\end{array}$ & $\begin{array}{l}\text { Quero } \\
\text { dormir } \\
\text { de botas } \\
\text { calçadas }\end{array}$ & $\begin{array}{c}\text { Queres } \\
\text { dar à luz } \\
\text { em } \\
\text { Marte? } \\
\text { Sim? } \\
\text { Não? }\end{array}$ & $\begin{array}{c}\text { Tantanta } \\
\text { ran-tan } \\
\text { Jesus }\end{array}$ & $\begin{array}{c}\text { Quero } \\
\text { voltar à } \\
\text { escola } \\
\text { num } \\
\text { Lamborghini }\end{array}$ & - & $\begin{array}{c}\text { Onde } \\
\text { estão as } \\
\text { r a p i d i - } \\
\text { nhas } \\
\text { de } \\
\text { escritório } \\
\text { de } \\
\text { antanho }\end{array}$ & \begin{tabular}{|c} 
Vamos a \\
ver se \\
isto \\
agora \\
corre em \\
condições
\end{tabular} & $\begin{array}{c}\text { A } \\
\text { vingança } \\
\text { serve-se } \\
\text { amarela }\end{array}$ & $\begin{array}{l}\text { Justin } \\
\text { Bieber } \\
\text { num } \\
\text { foguetão }\end{array}$ \\
\hline 'Outra Coisa' & \multicolumn{2}{|c|}{$\begin{array}{l}\text { Cavaco enfrenta } \\
\text { o vagalómetro! }\end{array}$} & \multicolumn{2}{|c|}{$\begin{array}{l}\text { O Prof. Marcelo comenta } \\
\text { Grécia, Educação } \\
\text { e BES }\end{array}$} & $\begin{array}{c}\text { Passos } \\
\text { Coelho fala } \\
\text { sobre a } \\
\text { Grécia... } \\
\text { mais ou } \\
\text { menos }\end{array}$ & \multicolumn{2}{|c|}{$\begin{array}{c}\text { O protesto } \\
\text { do Sr. Sem Glúten }\end{array}$} & \multicolumn{2}{|c|}{ A antevisão do dérbi } \\
\hline $\begin{array}{l}\text { 'Pensa } \\
\text { Rápido' }\end{array}$ & \multicolumn{2}{|c|}{ Vida em Marte } & \multicolumn{2}{|c|}{ Perder Coisas } & $\begin{array}{c}\text { Raciona- } \\
\text { mento } \\
\text { de água }\end{array}$ & \multicolumn{2}{|c|}{ Motas na faixa do bus } & \multicolumn{2}{|c|}{ Arrastar cadeiras } \\
\hline 'Portugalex' & \multicolumn{2}{|c|}{$\begin{array}{l}\text { Fórum: Era capaz de } \\
\text { beber água de cocó? }\end{array}$} & \multicolumn{2}{|c|}{$\begin{array}{c}\text { Cavaco Silva revela } \\
\text { conversas com } \\
\text { Ricardo Salgado }\end{array}$} & $\begin{array}{c}\text { Cavaco Sil- } \\
\text { va } \\
\text { revela } \\
\text { conversas } \\
\text { com Ricar- } \\
\text { do } \\
\text { Salgado }\end{array}$ & \multicolumn{2}{|c|}{$\begin{array}{c}\text { Fórum - A vitória do } \\
\text { Syriza já está a mudar } \\
\text { a sua vida? }\end{array}$} & \multicolumn{2}{|c|}{$\begin{array}{l}\text { Agente imobiliária } \\
\text { de jihadistas } \\
\text { em Portugal }\end{array}$} \\
\hline $\begin{array}{l}\text { 'Tubo de } \\
\text { Ensaio' }\end{array}$ & \multicolumn{2}{|c|}{$\begin{array}{c}\text { Resumo } \\
\text { da 1. ' semana } \\
\text { dos malucos gregos }\end{array}$} & \multicolumn{2}{|c|}{ A carta de Duarte } & $\begin{array}{l}\text { Xenofobia } \\
\text { de } \\
\text { matrícula }\end{array}$ & \multicolumn{2}{|c|}{ Saber aplicar baton } & \multicolumn{2}{|c|}{$\begin{array}{l}\text { Os hepáticos que } \\
\text { paguem a crise }\end{array}$} \\
\hline
\end{tabular}

Quadro 1 - Programas analisados com referência central (sublinhado carregado); circunstancial (sublinhado suave); ou ausente à atualidade (branco).

A propósito da relação que os ouvintes estabelecem com os formatos humorísticos na rádio, podemos recordar um estudo já apresentado do projeto "Estação NET", que reflete justamente sobre esta questão com 106 indivíduos (Ribeiro, 2014) ${ }^{21}$. Apenas dois indivíduos desta amostra afirmaram nunca ter ouvido um pro-

21 Um inquérito por questionário foi disponibilizado entre fevereiro e março de 2014, utilizando o software Limesurvey, do LASICS (Laboratório de Sistemas de Informação para a Investigação em Ciências Sociais), do Instituto de Ciências Sociais da Universidade do Minho, através de uma ligação inserida nas páginas do Facebook das principais rádios nacionais, como Antena 1, RR, RFM, Rádio Comercial, M80, bem como através da lista de contactos e site do projeto de investigação Estação NET. A expectativa consistia, portanto, em encontrar nestes espaços online o maior número de ouvintes, ao longo de todo o mês de março de 2014. No total, registaram-se 106 respostas completas, obtidas por 64 mulheres e 37 homens, num grupo de inquiridos com idades que variam entre os 19 e 77 anos, 
grama de humor na rádio, pelo que as seguintes respostas refletem os depoimentos de 104 ouvintes.

Questionados sobre que aspetos Ihes ocorrem perante os vocábulos 'rádio' e 'humor', houve uma notória associação dos dois termos aos formatos humorísticos da rádio. Neste caso, destacaram-se sobretudo 'Mixórdia de Temáticas' e 'O Homem que Mordeu o Cão'. 0 protagonismo dos comediantes leva a que 36 comentários tenham recordado alguns dos mais emblemáticos atualmente, como Ricardo Araújo Pereira, Nilton ou Luís Franco-Bastos, entre outros. Podemos ainda destacar duas situações que revelam bem o poder da rádio no período matinal, que consiste precisamente em inscrever o humor ao início do dia.

No que toca à frequência com que os inquiridos acompanham o humor na rádio, os inquiridos demonstraram um acompanhamento regular destes formatos. A grande concentração verifica-se entre os que ouvem entre 'uma a duas vezes por semana' e 'mais do que uma vez por dia', traduzindo a inclinação de 83 dos 106 indivíduos, isto é, $78,30 \%$ do total. No entanto, a indicação mais expressiva reside numa escuta entre 'três a seis vezes por semana', o que configura uma atenção regular a estes programas.

Relativamente à avaliação da qualidade que é feita por estes ouvintes aos programas de humor na rádio, 0 Gráfico 1 oferece alguns dados relevantes:

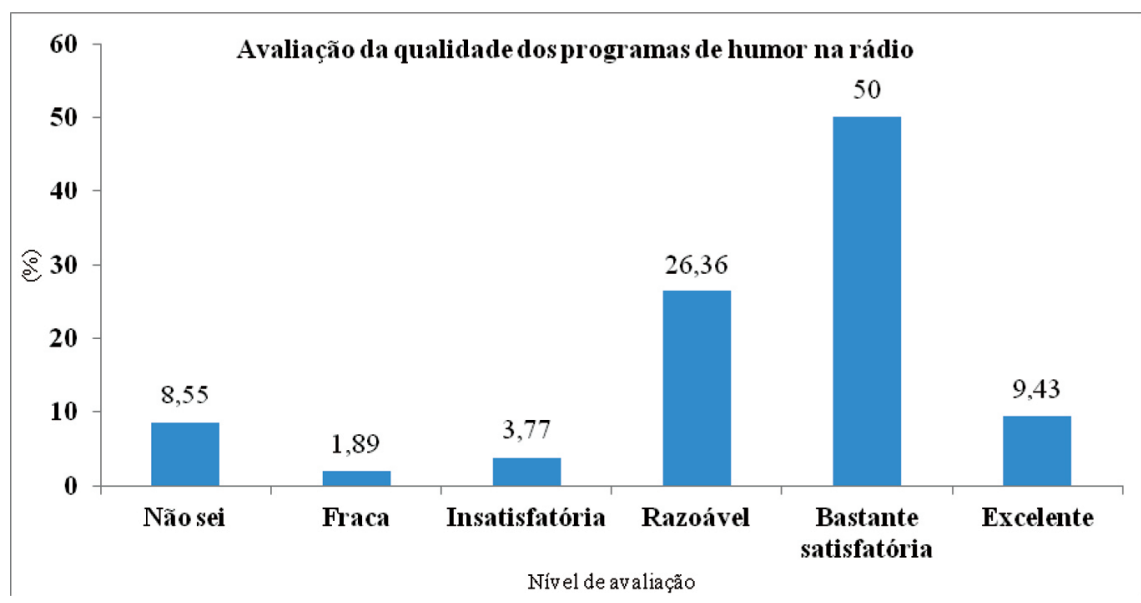

Gráfico 1 - Avaliação da qualidade dos programas de humor na rádio pelos inquiridos. Fonte: Ribeiro, 2014

Os resultados indicam claramente um nível positivo de satisfação perante os programas de humor na rádio sendo que metade dos inquiridos (50\%) atribui uma qualidade "bastante satisfatória" aos referidos espaços e 26,36\% classifica-os de "razoável". Apenas 9,43\% dos ouvintes avalia como "excelente". Também parece ser praticamente residual o nível de desagrado $(5,66 \%)$.

sendo 0 valor médio de 34 anos. As respostas foram dadas a partir de Portugal (97) e apenas 6 do estrangeiro. Três inquiridos não responderam às questões 'Sexo' e 'Local de residência'. 
Na parte final do questionário surge uma questão que reforça empiricamente uma ideia que temos vindo a desenvolver neste texto ${ }^{22}$. Desafiados a elaborar um comentário relativamente breve sobre possíveis sugestões a incluir em apostas futuras quanto à dinamização de espaços humorísticos na rádio, os resultados obtidos estão representados na Tabela 4.

\begin{tabular}{|l|r|}
\hline \multicolumn{1}{|c|}{ Sugestões } & \multicolumn{1}{c|}{ Frequência } \\
\hline Mais programas de crítica da atualidade & 19 \\
\hline Promover as crónicas de autor & 4 \\
\hline Aumentar formatos de sátira política & 4 \\
\hline Apostar num género de info-entretenimento & 1 \\
\hline Utilizar o humor negro & 1 \\
\hline Formatos com fails de personalidades públicas & 1 \\
\hline Adotar mais formatos de talkshow & 1 \\
\hline Criar sketches humorísticos de 60 minutos & 1 \\
\hline Integrar a opinião das pessoas & 1 \\
\hline Resposta inválida & 3 \\
\hline Total & 36 \\
\hline
\end{tabular}

Tabela 4 - Sugestões de dinamização dos programas de humor na rádio.

Apenas 34\% dos inquiridos responderam a esta questão (36 em 106) e a tendência reforça a necessidade de promover espaços humorísticos que possam servir de crítica à atualidade, um aspeto que se adequa ao propósito genérico deste texto. De facto, não é possível justificar concretamente se estes 19 ouvintes entendem que a atual oferta radiofónica humorística deste tipo decorre em número inferior ao que expectável ou se é necessário solidificar os que já existem. De qualquer modo, encontramos aqui uma base que procura uma maior presença de assuntos de crítica sobre a atualidade no humor. A sátira política e as crónicas de autor, seguindo exemplos já observados anteriormente, também foram incluídas neste leque de sugestões. A título mais pontual, algumas ideias que recuperam aspetos como a criação de rubricas em torno de momentos embaraçosos de celebridades, a aposta num humor negro, a necessidade de integrar a voz do público no discurso humorístico, ou mesmo a dinamização de um talkshow radiofónico.

\section{Conclusão}

A questão que conduziu esta investigação era a seguinte: será o humor uma forma de se manter informado? Os resultados aqui apresentados não permitem chegar a uma conclusão clara sobre isso, mas sugerem que isso possa acontecer. Numa altura em que tablets e smartphones com acesso à Internet se vulgarizam, a forma

220 questionário mediu também outras variáveis: a frequência de escuta de programas de humor; o contexto habitual onde decorre essa escuta; a valorização que atribuem à qualidade dos programas e à aposta da rádio para esses formatos. 
como acedemos à informação sobre a atualidade vai mudando. Como são informadas as pessoas na era digital? A subversão própria do humor pode ser uma forma para chegar às pessoas, eventualmente até a um público mais jovem.

Apesar de incluir amostras pequenas, este trabalho deixa pistas interessantes e confirma o ponto de partida: muitos dos programas analisados exploram assuntos da atualidade. Os ouvintes apreciam este tipo de programas e gostariam que eles satirizassem ainda mais os assuntos que marcam a realidade mediática. Outro dado curioso que surge neste estudo exploratório é a presença da totalidade dos programas em formato podcast e disponível na Internet. Isto possibilita ao ouvinte seguir os seus programas favoritos na altura que mais Ihe convier. A Internet funciona não só como propagação, mas também como plataforma - sobretudo através do Facebook - para, em alguns dos programas, estabelecer contacto com os ouvintes e partilha com outros elementos da audiência.

Para futura investigação, seria eventualmente importante considerar um período de observação mais alargado. Neste sentido, uma abordagem mais completa deveria contemplar a realização de entrevistas com os responsáveis pelos programas, para conhecer a perspectiva de quem cria. Nomeadamente, tentar perceber a natureza das reações dos ouvintes ao programa, a influência dos ouvintes na construção do programa, se existe alguma preocupação em contextualizar um acontecimento que está a ser comentado, entre outros. Seria também interessante conversar com o provedor do ouvinte, explorando a hipótese de que o tom satírico nem sempre é aceite por todos de forma pacífica e, por isso, os programas de humor podem ser um dos principais motivos de queixas remetidas para o provedor. De facto, apesar de ficar evidente uma certa visão positiva que os autores têm relativamente a estes programas, os acontecimentos ocorridos no início de 2015 em Paris, que culminaram no assassinato de jornalistas na redação do jornal satírico francês Charlie He$b d o$, deixaram em evidência a polémica que o humor pode desencadear, inclusive levando a posições mais extremadas.

Em suma, parece claro que ainda existe um terreno fértil para continuar a explorar o potencial do humor como ferramenta pedagógica, subscrevendo-o à luz dos entendimentos da Educação para os Media, e à dimensão do conhecimento do mundo que nos rodeia, nomeadamente nesta ligação à rádio. Não só ficou evidente a importância da dimensão da informação e da atualidade, como também a utilização muito frequente de formatos jornalísticos, como a entrevista, reportagem, noticiário ou debate.

\section{Referências}

Aladro, E. (2002). El humor como medio cognitivo. CIC Cuadernos de Información y Comunicación, 7, 317-327.

Armstrong, P. (2005). Satire as critical pedagogy. In J. Caldwell (Ed.), What a difference a pedagogy makes: Researching lifelong learning and teaching. Conference proceedings, Vol. 1. Stirling: Centre for Research in Lifelong Learning, University of Stirling. Acedido em janeiro de 2015, em http://www.education.leeds.ac.uk/research/ uploads/37.pdf 
Cantante, F. (2007). A graça sociológica do humor. CIES e-Working Paper, n. ${ }^{0}$ 33/2007. Lisboa, CIES-ISCTE. Acedido em fevereiro de 2015 em https://repositorio.iscte-iul.pt/handle/10071/603

Dias da Silva, P. \& Garcia, J. L. (2012). YouTubers as satirists, humour and remix in online video. JeDEM, 4(1), 89-114.

Garcia, A., Seglem, S. \& Share, J. (2013). Transforming teaching and learning through critical media literacy pedagogy. LEARNing Landscapes, 6(2), Spring 2013. Acedido em janeiro de 2015 em http://www.learninglandscapes.ca/images/documents/I-no12/garcia.pdf

Gray, J. (2005). Television teaching: Parody, The Simpsons, and media literacy education. Critical Studies in Media Communication, 22(3), 223-238.

Lunt, P. \& Livingstone, S. (2012). Media regulation, governance and the interest of citizens and consumers. London: Sage.

Lockyer, S. \& Pickering, M. (Eds.) (2005). Beyond a joke: The limits of humour. Basingstoke: Palgrave Macmillan.

Lockyer, S. (2010), Dynamics of social class contempt in contemporary British television comedy. Social Semiotics, 20(2), 121-138.

Meddaugh, P. M. (2010). Bakhtin, Colbert, and the center of discourse: Is there no "truthiness" in humor?. Critical Studies in Media Communication, 27(4), 376-390.

Pereira, L. (no prelo). How to use parody and humour to teach digital literacy. In M. N. Yildiz, \& J. Keengwe (Eds.), Handbook of research on media literacy in the digital age. Hershey: IGI Global.

Pereira, L., Pinto, M. \& Pereira, S. (2009). Humor como estratégia de literacia mediática proposta de abordagem dos media em contexto escolar. Comunicação apresentada durante o CICOM: Braga, Universidade Católica Portuguesa.

Pereira, S., Pinto, M., Madureira, E. J., Pombo, T., Guedes, M., Santos, L. F. \& Pedroso, J. V. (2014). Referencial de educação para os media para a educação pré-escolar, o ensino básico e o ensino secundário. MEC/DGE.

Pereira, S., Pereira, L. \& Tomé, V. (2011). 25+1 - Agenda de actividades de educação para os média. Braga: CECS, U. Minho e Gabinete para os Meios de Comunicação Social.

Pereira, S., Pinto, M. e Pereira, E. (2009). A televisão e as crianças - um ano de programação na RTP1, RTP2, SIC e TVI. Lisboa: Entidade Reguladora para a Comunicação.

Pinto, M. (2000). A televisão no quotidiano das crianças. Porto: Afrontamento Ed.

Pergher, G. K., Grassi-Oliveira, R., Ávila, L. M. \& Stein, L. M. (2005). Memória, humor e emoção. Revista de psiquiatria do Rio Grande do Sul. 28(1), 61-68.

Portela, P. (2015), A voz do utilizador na mediamorfose da rádio: A interactividade e os consumos radiofónicos do início do séc. XXI. Tese de doutoramento, Instituto de Ciências Sociais, Universidade do Minho, Portugal.

Produções Fictícias, Mandala (1996-2010). 'Contra-Informação', RTP.

Produções Fictícias (2013- ). 'Inimigo Público', Público.

Ribeiro, F. (2014). Vozes que fazem rir e ouvir melhor. 0 humor como estratégia de revitalização da rádio. Comunicação apresentada durante o II Congresso Mundial da Confederação Ibero-Americana de Ciências da Comunicação (CONFIBERCOM), 13 a 16 de abril de 2014, Universidade do Minho, Braga. 
Ribeiro, F. (2008). A rádio e os ouvintes: A fórmula de uma relação bipolar. Dissertação de mestrado, Instituto de Ciências Sociais, Universidade do Minho, Portugal.

Shelton, A. N. (2014). The power of parody and satire in the 21st century English classroom. Honors Projects. Paper 131.

Sousa, H. \& Silva, E. C. (2009). Keeping up appearances: Regulating media diversity in Portugal. International Communication Gazette, 71(1-2), 89-100.

Stark, C. (2003). "What, me worry?": Teaching media literacy through satire and Mad Magazine. The Clearing House, 76(6), 305-309.

Young, D. G. (2004). Late-night comedy in election 2000: Its influence on candidate trait ratings and the moderating effects of political knowledge and partisanship. Journal of Broadcasting \& Electronic Media, 48(1), 1-22.

Young, D. G. (2008). The privileged role of the late-night joke: Exploring humor's role in disrupting argument scrutiny. Media Psychology, 11(1), 119-142.

Pereira, S., Pinto, M. Madureira, E., Pombo, T. \& Guedes, M. (2014). Referencial de educação para os media para a educação pré-escolar, o ensino básico e o ensino secundário", Acedido em janeiro de 2015, em http://dge.mec.pt/index.php?s=noticias\&noticia=857 